\title{
A hierarchical model for oxygen dynamics in streams
}

\author{
James E. Garvey, Matt R. Whiles, and Dennis Streicher
}

\begin{abstract}
Although oxygen frequently limits aquatic ecosystems, broad temporal-spatial oxygen dynamics in streams and consequences for aquatic life are poorly understood. In this perspective, we quantified dissolved oxygen (DO) concentrations $\left(\mathrm{mg} \cdot \mathrm{L}^{-1}\right)$ in six low-gradient streams in Illinois, USA, using semicontinuous data loggers at multiple sites during summer 2005 (a severe drought year) and summer 2006. We then interpreted these patterns in the context of known responses of stream organisms to DO. Daily median and minimum DO concentrations varied among sites, even within streams. Daily mean discharge $\left(\mathrm{m}^{3} \cdot \mathrm{s}^{-1}\right)$ explained as much as $63 \%$ of the variance in DO during both the drought and nondrought years, with increasing discharge (often concomitant with declining temperature) causing DO concentrations to increase in most large stream reaches and to decline in many small streams. Biological responses to this variation in DO are uncertain, although our review suggests that minimum daily concentrations within several of these streams may have been insufficient to sustain early life stages of aquatic organisms. We propose a hierarchical conceptual model for understanding DO within temperate streams, suggesting the following constraining factors in descending levels of organization: season, flow (and gradient) plus temperature, geomorphology, organic enrichment, and oxygen demand of macro-organisms.
\end{abstract}

Résumé : Bien que l'oxygène soit fréquemment un facteur limitant dans les écosystèmes aquatiques, on en comprend encore mal la dynamique à de grandes échelles temporelle et spatiale dans les cours d'eau et les conséquences pour la vie aquatique. Dans ce contexte, nous avons mesuré les concentrations $\left(\mathrm{mg} \cdot \mathrm{L}^{-1}\right)$ d'oxygène dissous (DO) dans six cours d'eau à pente faible de l'Illinois, É.-U., à l'aide d'enregistreurs de données à fonctionnement semi-continu à plusieurs sites durant les étés 2005 (une année de grande sécheresse) et 2006. Nous avons ensuite interprété les patrons obtenus en fonction des réponses connues des organismes aquatiques à DO. Les concentrations journalières médianes et maximales de DO varient d'un site à l'autre, même dans un même cours d'eau. Le débit journalier moyen $\left(\mathrm{m}^{3} \cdot \mathrm{s}^{-1}\right)$ explique jusqu'à $63 \%$ de la variance de DO, tant durant l'année de sécheresse que durant l'année sans sécheresse; un débit croissant (souvent accompagné de températures déclinantes) fait augmenter les concentrations de DO dans la plupart des grandes sections de cours d'eau et les fait baisser dans plusieurs petits cours d'eau. Les réponses biologiques à cette variation de DO restent incertaines, bien que notre survol indique que les concentrations journalières minimales dans plusieurs de ces cours d'eau auraient pu être trop basses pour la survie des jeunes stades des organismes aquatiques. Nous proposons un modèle conceptuel hiérarchique pour la compréhension de DO dans les cours d'eau tempérés et nous suggérons une liste des facteurs contraignants selon un niveau d'organisation descendant, soit la saison, le débit (et la pente) plus la température, la géomorphologie, l'enrichissement organique et la demande en oxygène des macroorganismes.

[Traduit par la Rédaction]

\section{Introduction}

Oxygen is a limiting substance for most aquatic organisms. It is unique because an acute deficiency can lead to immediate and permanent effects at multiple levels of eco- logical organization from the individual to the ecosystem (Wu 2002). For most other limiting substances, the impact of deficiencies is typically lagged and reversible and usually restricted to a subset of the organisms. Oxygen is poorly soluble in water, particularly at high temperatures, and demand

Received 2 February 2007 Accepted 6 October 2007. Published on the NRC Research Press Web site at cjfas.nrc.ca on 30 November 2007. J19808

J.E. Garvey ${ }^{1}$ and M.R. Whiles. Department of Zoology, Fisheries and Illinois Aquaculture Center, and Center for Ecology, Southern Illinois University, Carbondale, IL 62901, USA.

D. Streicher. Illinois Association of Wastewater Agencies and Department of Water and Wastewater, Elmhurst, Illinois, USA.

${ }^{1}$ Corresponding author (e-mail: jgarvey@ siu.edu). 
is not limited to the biota. Because of its strong electronegativity, oxygen is critical in many nonbiological chemical reactions. Therefore, competition for oxygen occurs not only among organisms, but also between the biotic and abiotic components of ecosystems. Human activities have long been known to alter oxygen dynamics in freshwater habitats (Carlson 1977; Cooper 1993) and thus affect this element's relative availability to physical and biological processes.

In our view, the contemporary understanding of oxygen dynamics differs between standing and flowing water systems. In lakes, temporal and spatial changes in oxygen are fairly well understood. For example, a major limnology textbook (Wetzel 2001) devotes 14 pages to a discussion of changes in vertical and horizontal distribution of oxygen in lakes as a function of season, wind mixing, and nutrients. The effects of oxygen distributions in lakes at the community level also are well understood (Tonn et al. 1990; Danylchuk and Tonn 2003). Conversely, the dynamics of oxygen in running waters merit less than one page in the popular limnology text (Wetzel 2001; also see the single page in Hauer and Lamberti (2006) and a half page in Cushing and Allan (2001)). Further, as we identify herein, the biological implications are not well understood or classified.

The lack of clear expectations for oxygen in streams is surprising given the ecological importance of this element in water. Quantitative models exist for determining oxygen dynamics in flowing water, most notably the US Environmental Protection Agency's QUAL2E black-box model (Barnwell and Brown 1987). However, these and other models seem to fare poorly when predicting dynamics beyond physically simple reaches (Vellidis et al. 2006).

The US federal-level Clean Water Act, passed in the early 1970 s, was in part a response to the effect of cultural eutrophication on oxygen availability. Since then, legal guidelines for oxygen in streams in the US have been developed based on the best available biological information, incorporating chronic and acute thresholds of dissolved oxygen concentrations that aquatic organisms can tolerate (Chapman 1986). However, these expectations were developed without knowledge about the true baseline concentrations for oxygen in running waters. In other words, we know very little about the joint physical and biological expectations for oxygen availability in most streams. As watersheds are further transformed by urban development and interest in agriculture as a source of alternative energy increases, the need for policymakers to have access to sound expectations for oxygen concentrations, particularly in warm, low-gradient streams, is heightened.

Geographic location, season, and the physical characteristics of flowing water provide some general expectations for dissolved oxygen concentrations. The solubility of oxygen declines with increasing temperature (Wetzel 2001), i.e., oxygen is typically (but not always) more limiting during summer in temperate regions and perhaps year-round at lower latitudes. Flow velocity interacts with factors such as water depth, streambed morphology, and stream surface area to influence the exchange between water and the atmosphere, re-oxygenating streams (Owens et al. 1964). High-gradient streams should rarely experience hypoxia due to high re- aeration rates (Owens et al. 1964). Conversely, low-gradient systems that experience a reduction in average flow velocity and a concomitant decline in discharge may be more susceptible to declining oxygen.

Low-gradient (less than $1 \%$ slope) streams are common in glaciated and typically farmed landscapes. Our survey of $133892 \mathrm{~km}$ of Illinois streams in the US National Hydrography Data Set $(1: 100000$ scale) revealed that $97 \%$ of these reaches had less than a $0.1 \%$ slope. Re-aeration of these systems should be less certain than in higher-gradient streams during regular flow (see Owens et al. 1964), and oxygen demand may be related to other features that either deplete or increase oxygen such as nutrient burden, habitat quality (e.g., substrate types, sinuosity, etc.), and algal growth. Most information about oxygen in these systems is typically limited to single point estimates (i.e., grab samples or spot measurements) that are limited spatially, and there are obvious limitations to this approach. Oxygen may vary dramatically temporally with photosynthetic and metabolic activity of autotrophs (Wang et al. 2003). Moreover, features that affect oxygen concentration such as re-aeration, light penetration, stream width and depth, and organic matter retention vary spatially (e.g., between riffles and pools; Cushing and Allan 2001), further complicating expectations. Clearly, categorizing streams based on expectations for oxygen concentrations is challenging. Still, given the dependence of most organisms on a steady oxygen supply, oxygen in low-gradient streams must be typically nonlimiting, otherwise most stream taxa would be adapted to low oxygen conditions (e.g., anaerobic respiration would be a common tactic), which is generally not the case (Smale and Rabeni $1995 a, 1995 b$; see below).

The advent of reliable and relatively inexpensive methods for automatic logging of oxygen concentrations is a boon for scientists and resource managers interested in quantifying and understanding dynamics and availability of oxygen to aquatic organisms. However, the availability of advanced technology should not solely drive research. Rather, an organizational framework for research is needed. We first quantified temporal and spatial patterns of oxygen in several lowgradient streams in glaciated Illinois. Within one river, we also explored flow-related patterns during a drought year and a nondrought year. In the context of these physical patterns, we reviewed the range of biological needs of stream organisms for oxygen, with a focus on life history patterns. From these results, we developed a hierarchical conceptual model for dissolved oxygen in streams, with a call for research determining linkages among oxygen, hydrology, and other features of the physical template, water quality, and distributions of organisms.

\section{Dynamics of oxygen in flowing water}

We obtained semicontinuous oxygen concentration data from six streams of varying size in northern and central Illinois (Fig. 1). In the Fox River (mean daily discharge per annum = $700 \mathrm{~m}^{3} \cdot \mathrm{s}^{-1}$ ), three sites were monitored during May through July in 2005 and during May through September in 2006. Eight sites in the East Branch, West Branch, and Main Branch DuPage River (mean daily discharge per annum $=74 \mathrm{~m}^{3} \cdot \mathrm{s}^{-1}$ ) 
Fig. 1. River reaches within northern and central Illinois in which semicontinuous dissolved oxygen data were quantified during 2005 and 2006. Thin lines are river segments that have been listed as impaired by the Illinois Environmental Protection Agency (ILEPA 2004). Thicker highlighted segments are those reaches in proximity to the sampling sites. Each sampling site is identified by a circle. Sites within each river are denoted sequentially in number from north to south (i.e., Salt 1 is northernmost, Salt 3 is southernmost). Background shading represents elevation ranging from about $400 \mathrm{~m}$ (white) to $100 \mathrm{~m}$ (dark grey) above sea level.

\section{Longitude}

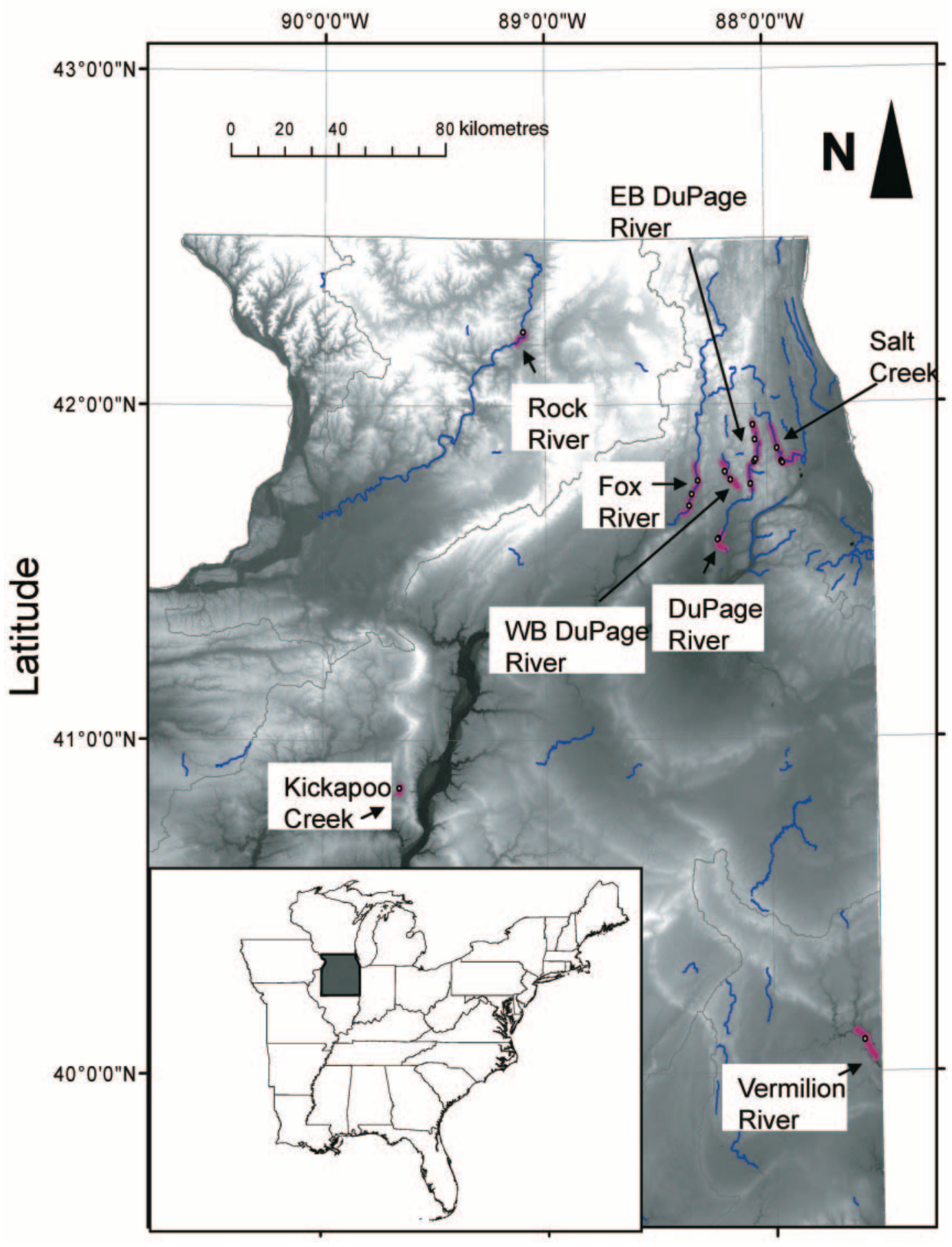

were monitored during June through July 2006. Three sites in Salt Creek (mean daily discharge per annum $=1.7 \mathrm{~m}^{3} \cdot \mathrm{s}^{-1}$ ) and one site in each of Kickapoo Creek $\left(46 \mathrm{~m}^{3} \cdot \mathrm{s}^{-1}\right)$ and the Vermilion $\left(609 \mathrm{~m}^{3} \cdot \mathrm{s}^{-1}\right)$ and Rock rivers $\left(3780 \mathrm{~m}^{3} \cdot \mathrm{s}^{-1}\right)$ also were moni- tored during summer 2006. These river sites ranged in assessed quality, with several of the sites within reaches listed as not meeting Illinois Environmental Protection Agency (ILEPA) benchmarks for aquatic life use, with low oxygen cited as a 
Fig. 2. Semicontinuous (30-60 min intervals) dissolved oxygen concentrations $\left(\mathrm{mg} \cdot \mathrm{L}^{-1}\right)$ in central and northern Illinois stream sites during 2005 and 2006. On each panel, a $5 \mathrm{mg} \cdot \mathrm{L}^{-1}$ threshold is depicted with a horizontal line. Current Illinois statute does not allow streams to fall below this minimum value.

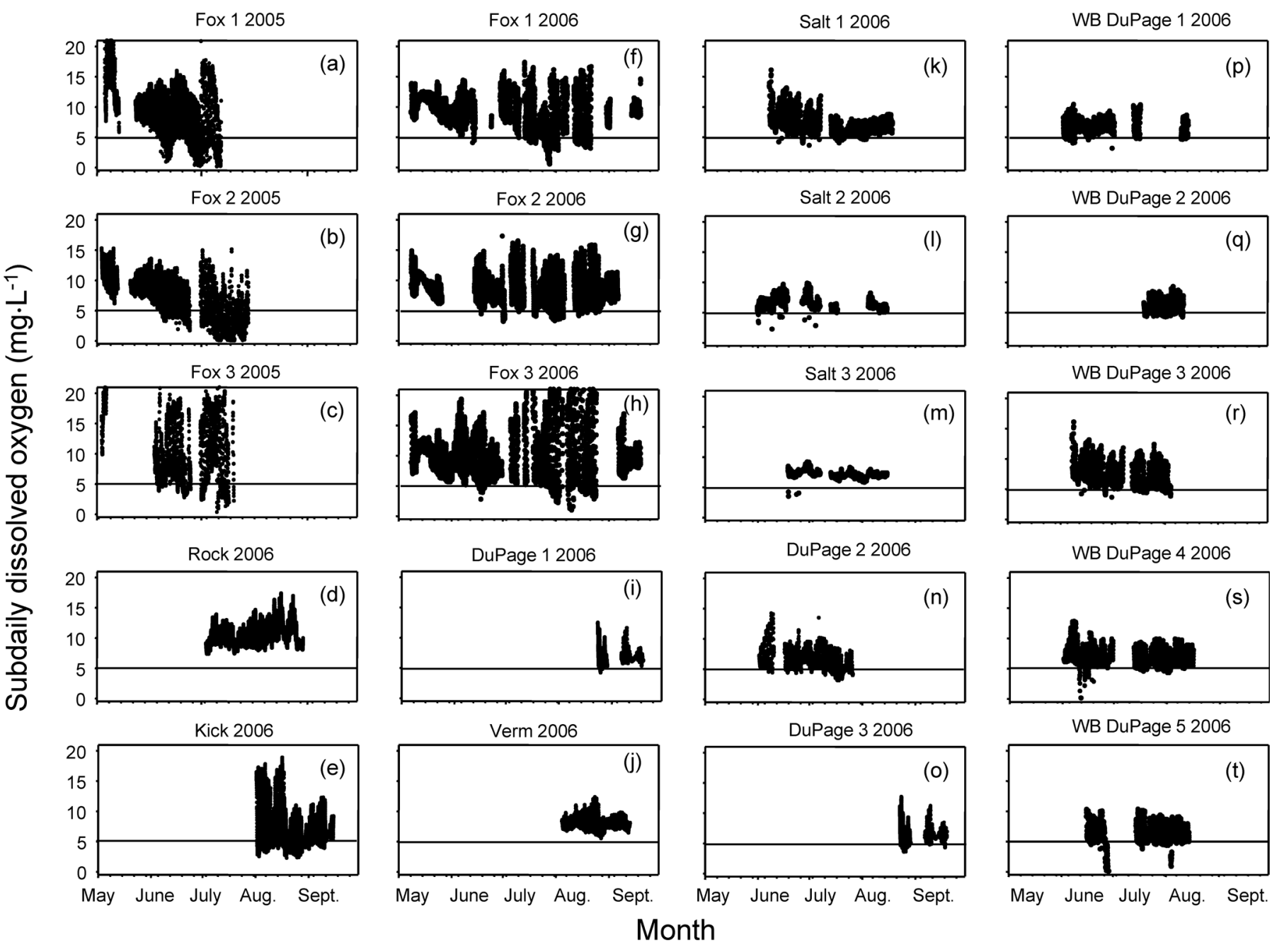

cause (i.e., oxygen declining below $5 \mathrm{mg} \cdot \mathrm{L}^{-1}$; ILEPA 2004; Fig. 1). The Illinois benchmark for oxygen is likely based on conclusions of Moore (1942, p. 322). All data were collected using semicontinuous monitoring data-logging sondes (3060 min interval; YSI (Yellow Springs, Ohio) or Hach Hydrolab (Loveland, Colorado)). Most of the probes were affixed to bridges, and all were placed at depths (typically $>1 \mathrm{~m}$ above the bottom) that ensured that they were continuously submerged.

The intent of our analysis was not to identify mechanisms, but rather to determine how dissolved oxygen varied between years and among reaches to identify expectations for median and minimum concentrations through time. For sites within stream reaches in which we had consistent data for June through August, we generated a monthly average of the daily median oxygen concentrations. We determined whether these averages differed monthly and among sites using nonmetric multidimensional scaling ordination (NMS; McCune and Grace 2002). A Sorensen distance measure was used, and axes were selected by the combination that generated significantly lower stress than randomized data sets (PCORD, version 4.14; MJM Software, Gleneden Beach, Oregon, USA). We expected that oxygen concentrations would be more similar at sites within rivers than among rivers.
Also, we expected that sites would separate based on month of summer due to temperature and flow differences that occur within this season. Typically, flow declines, temperatures increase, and stream respiration increases as summer progresses, reducing daily minimum oxygen concentrations. Median daily oxygen concentrations might rise at the same time because of increased autotrophy.

Daily discharge differed among sites and was thus included in the analysis to account for its potential effect on dissolved oxygen concentration. Daily mean discharge values were obtained from United States Geological Survey (USGS) gauging stations nearest each sampling site. We used linear regressions with the appropriate transformations when necessary to determine how median and minimum daily oxygen concentrations varied with discharge. Daily mean temperature, which may covary with oxygen, also was regressed against discharge at each site. The expectation was that a flow-related decline in summer temperatures would increase oxygen concentrations.

The slopes of the relationships between oxygen and discharge provided useful information. For example, a positive slope would indicate that oxygen increased with increasing discharge. In particular, we were interested in determining 
Fig. 3. Scores for the nonmetric multidimensional scaling (NMS) test of average daily median dissolved oxygen concentrations within central and northern Illinois stream sites during 2006. Sites separated significantly $(p<0.05)$ along one NMS axis.

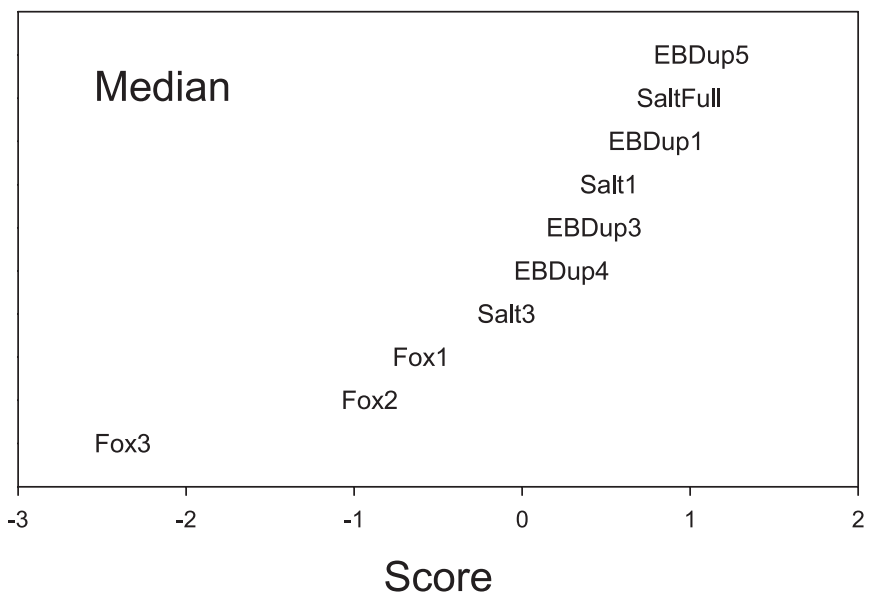

how stream size affects these slopes because small streams with high surface areas relative to volume should re-aerate more rapidly than large counterparts (Owens et al. 1964). We used per annum mean daily discharge as an index of stream size (i.e., larger streams generate greater average flow). A two-dimensional Kolmogorov-Smirnov test (2DKS) determined the stream size at which the change in discharge either increased or decreased oxygen concentrations (Garvey et al. 1998).

During 2005 and 2006, daily dissolved oxygen patterns differed markedly among river reaches (Fig. 2). Minimum concentrations reached near zero in some reaches while never declining below $5 \mathrm{mg} \cdot \mathrm{L}^{-1}$ in others (Vermilion and Rock Rivers; Fig. 2). No pattern between ILEPA impairment designation and oxygen dynamics was evident. For example, Kickapoo Creek routinely experienced concentrations below $5 \mathrm{mg} \cdot \mathrm{L}^{-1}$, the minimum allowable dissolved oxygen concentration in Illinois, although it was not listed as impaired (Figs. 1 and 2). Conversely, Rock River was listed as impaired by ILEPA because of low oxygen but never experienced low concentrations (Fig. 2). For the subset of data available in 2006, the NMS revealed that one axis was sufficient for describing the monthly median concentrations (Fig. 3). Sites separated on the axis, but monthly scores did not (Fig. 3). Scores for the Fox River sites were separate from the other sites, with Fox River site 3 being the most different (Fig. 3). No meaningful structure was found among sites or dates for minimum concentrations. Daily dissolved oxygen concentrations among reaches varied greatly during summer, with low values consistently occurring during night and dawn and high values (exceeding 100\% saturation) occurring during the day (Fig. 4). Values were consistently high in the spring and fall (Fig. 4).

Low discharge comprised a much greater proportion of the drought (2005) than nondrought (2006) year in Fox River (Fig. 5). However, during both years, daily discharge explained as much as $63 \%$ of the variance in minimum daily dissolved oxygen concentrations, with concentrations increasing with discharge (Fig. 6). Daily median concentrations in Fox River de-
Fig. 4. Box plots of hourly dissolved oxygen concentrations in central and northern Illinois stream sites during 2005 and 2006: (a) May, (b) June, (c) July, (d) August, (e) September. $N=$ 22746 across all panels. Line in center of box is the median; upper and lower bounds of boxes are the 75th and 25th percentiles; upper and lower bounds of whiskers are 90th and 10th percentiles. Solid points are outliers.

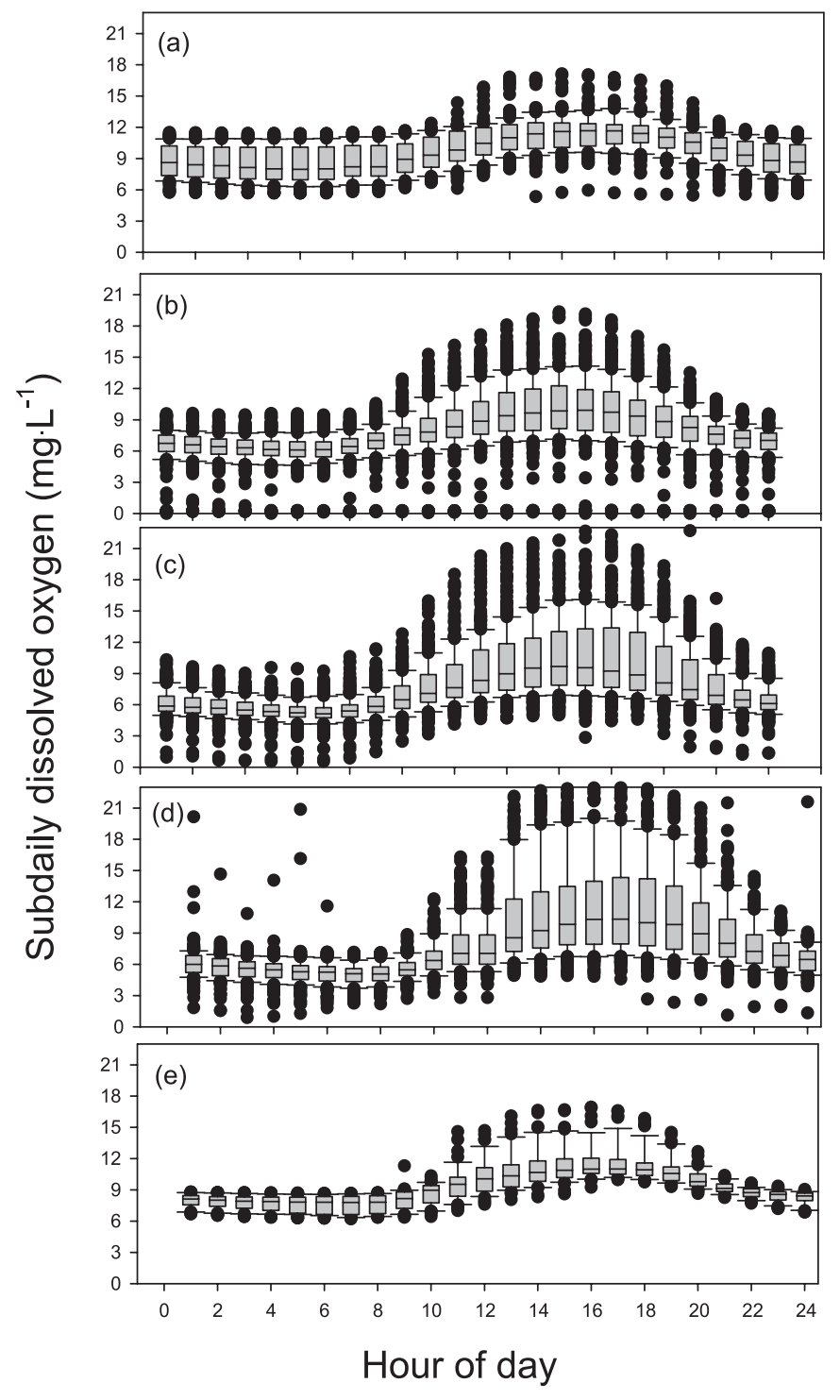

pended less on discharge (Fig. 6). For other stream reaches in 2006, median oxygen concentrations were often negatively related to discharge (Table 1). Of the 10 stream segments where dissolved median or minimum daily oxygen concentrations increased with increased flow, increased flow also reduced temperature in nine of them (Table 1). Of the remaining segments where oxygen either declined or did not change with increased flow, temperatures either declined or did not change (Table 1). A decline in oxygen was never concomitant with an increase in temperature (Table 1).

Stream size also appeared to affect how dissolved oxygen changed in streams with changing discharge. Small streams with $<74 \mathrm{~m}^{3} \cdot \mathrm{s}^{-1}$ mean per annum daily discharge varied greatly in their response, with several declining in oxygen 
Fig. 5. Daily average discharge in the Fox River during 2005 through 2006.

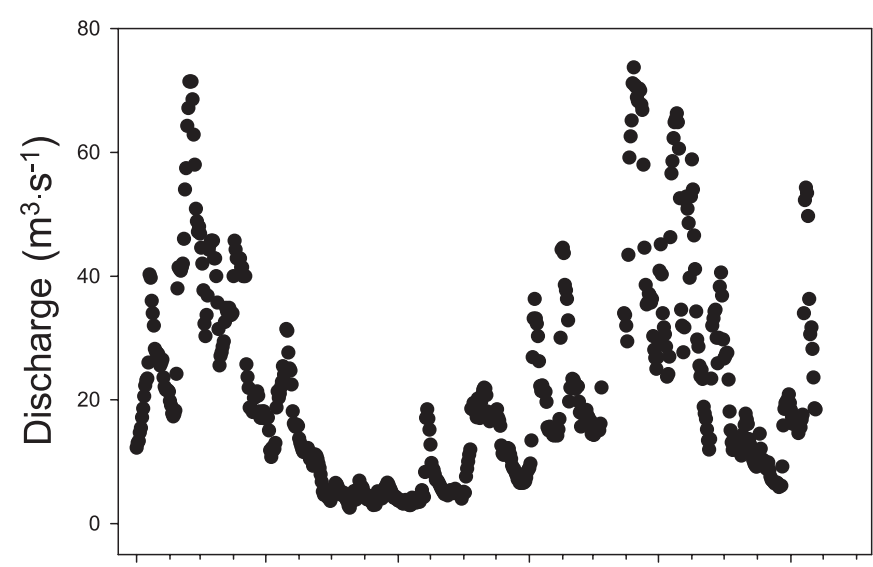

Jan. 2005 May 2005 Sept. 2005 Jan. 2006 May 2006 Sept. 2006

\section{Date}

concentration as discharge increased (2DKS, $p=0.01$; Fig. 7). In larger streams, a rise in discharge appeared to either have less impact or increase oxygen concentrations (Fig. 7).

In summary, increased temperature-dependent oxygen solubility and perhaps re-aeration likely elicit a strongly positive oxygen response in many streams during summer. Conversely, rising temperature with increased flow is probably not responsible for declining oxygen in other streams. The difference among streams of different sizes suggests that flow-related increases in dissolved solids or intrusion by hypoxic groundwater reduce oxygen concentrations in smaller systems with less total stream flow.

Placing simultaneously logged dissolved oxygen patterns across a variety of streams and flow conditions allowed us to generate some expectations for low-gradient streams of the agricultural and urban east-central North America. Dissolved oxygen concentrations vary greatly among sites, and patterns are similar among sites within reaches in some rivers but not in others. Although patterns of dissolved oxygen are likely affected by many attributes such as stream morphology and water quality, much of the variation (both positive and negative responses) in many of the streams could be explained by daily discharge, particularly in Fox River during both the drought and nondrought years.

The ILEPA typically identifies impairment by the presence of an assemblage of fish and invertebrates that are indicative of degraded systems and the absence of intolerant taxa (ILEPA 2004). Patterns of oxygen at the sites we monitored were not good indicators of impairment in this sense, suggesting that biological indicators of impairment and oxygen dynamics might not always be tightly linked. This is further supported by another study exploring semicontinuous patterns of oxygen in Illinois streams, which found that one of the most biologically intact streams in Illinois, Lusk Creek, routinely experienced concentrations below $4 \mathrm{mg} \cdot \mathrm{L}^{-1}$ (Groschen and King 2005). Of course, all of this is speculative until field patterns between macro-organisms and daily and seasonal oxygen dynamics are better understood. As we suggest in the following sections, the discipline of stream ecology is facing a challenge that needs to be addressed with an organized research approach.

\section{Biological responses to oxygen}

Because of the importance of oxygen to respiration, aquatic organisms must be sensitive to its abundance. Given the wide range of oxygen conditions in Illinois streams, responses at the individual, community, and ecosystem levels of organization should be predictable. In lake systems, how oxygen affects species assemblages in ice-covered lakes is well understood (Tonn and Paszkowski 1986). Further, the seasonal succession of lake ecosystems is strongly linked to the dynamics of wind mixing, oxygen, temperature, and other physical factors (see Wetzel 2001). Conversely, in streams, we are still left struggling with the implications of the temporal and spatial patterns of oxygen we quantified in Illinois streams. In other words, how much oxygen is enough and how does tolerance to low levels vary among stream organisms?

The evidence to date suggests that the oxygen requirements of organisms and associated life stages reflect the physical template in which they are expected to reside. Many fishes complete most of their reproduction during spring (Scott and Crossman 1998), when cool temperatures and a spring flood pulse ensure high DO concentrations. The pattern for Fox River during May 2005 and 2006 supports the supposition that oxygen is generally not limited during spring (Fig. 2). It does appear that many fishes have early life stages that are less tolerant to low oxygen than juvenile and adult stages (Perterka and Kent 1976).

Differences in oxygen tolerance among benthic macroinvertebrates should lend insight into the linkage between habitat needs and oxygen requirements. Lethal effects of low oxygen are obvious and well documented for many taxa, particularly more sensitive taxa such as members of the Ephemeroptera, Plecoptera, and Trichoptera (Fox et al. 1937; Nebeker 1972; Gaufin 1973). Lethal minima range widely among taxa, with the concentration causing $50 \%$ mortality typically being $3-4 \mathrm{mg} \cdot \mathrm{L}^{-1}$ (reviewed by Chapman 1986). Similarly, tolerance to hypoxia ranges dramatically among freshwater mussels, a group that is of special concern because population declines are widespread and many species are now threatened, endangered, or extinct (Watters 1999). As with other organisms, tolerance to hypoxia reflects the habitat in which mussel species typically reside (Chen et al. 2001). Many biological oxygen limits must be considered within the context in which they were obtained. Most sensitive taxa often live in flowing water, which affects diffusion of oxygen into gills.

Important sublethal responses also occur. Growth declines because aerobic respiration declines; anaerobic respiration is energetically costly. Also, energy that would normally be used for growth and reproduction is shunted toward ventilation and (or) other mechanisms for increasing oxygen uptake (Fox and Sidney 1953; Erikson et al. 1996). Pesticides and other toxicants further reduce invertebrate tolerances to low oxygen conditions because they can alter respiration rates themselves (e.g., Maki et al. 1973; Kapoor 1976). The consequences of sublethal effects such as reduced growth are important at the population level because adult female size is 
Fig. 6. Daily median and minimum oxygen concentrations $\left(\mathrm{mg} \cdot \mathrm{L}^{-1}\right)$ as a function of discharge in the Fox River sites during 2005 and 2006. Detailed regression results are in Table 1.

Daily median

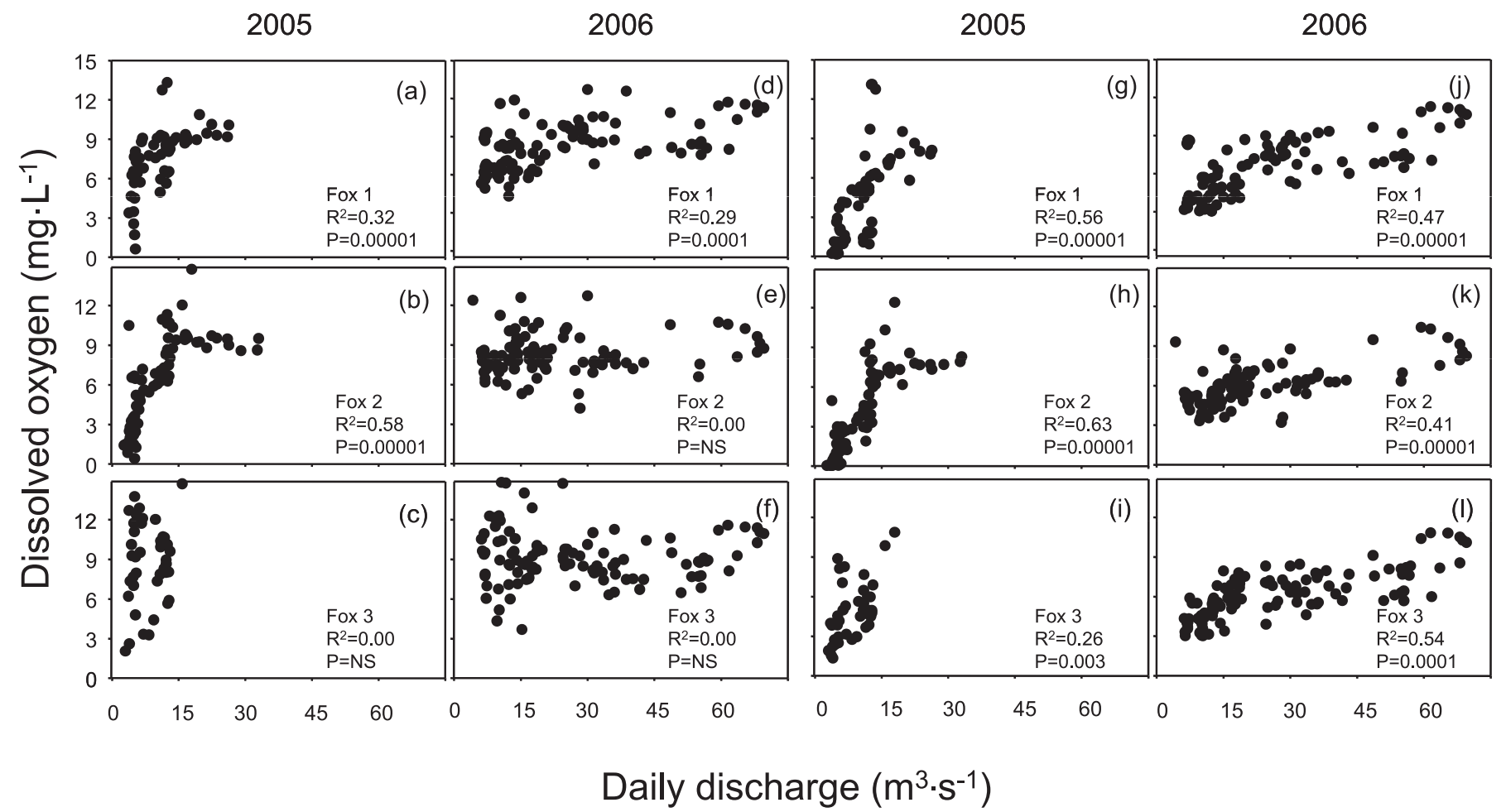

positively correlated with fecundity in a variety of aquatic organisms (Vannote and Sweeney 1980; Sweeney and Vannote 1981). Hypoxia also affects reproduction because it acts as an endocrine disruptor (Wu et al. 2003).

Few studies have successfully extrapolated tolerances derived in the laboratory to patterns in the field. However, Smale and Rabeni (1995a, 1995b) developed specific a priori oxygen criterion for Missouri streams and then linked this to laboratory-derived oxygen minima for common fishes (i.e., a hypoxia index). Mean dissolved oxygen and their laboratory-derived index were strongly correlated and differed between stable, steep Ozark-region streams and intermittent, lower-gradient, more agricultural Prairie-region streams. Oxygen concentration was the "template" affecting fish success. However, the relative contribution of humaninduced enrichment and natural factors to oxygen concentrations and hypoxia index values in the streams were unexplored.

Following Smale and Rabeni (1995a), we digitized embryonic and larval survival data from fig. 1 in Chapman (1986). We then analyzed the data for Chapman's "tolerant" warmwater species (largemouth bass, black crappie, white sucker, and white bass) and "intolerant" species (northern pike, channel catfish, walleye, and smallmouth bass) to isolate an "inflection" point in the curves of dissolved oxygen concentration versus percent survival (relative to controls). We used nonlinear regression to fit the best models to the tolerant (Michealis-Menten) and intolerant (logistic) species data.

For the nonlinear regression analysis, the curves fit the data moderately well (Fig. 8). The half-saturation dissolved oxygen concentration (similar to a lethal concentration $50 \%$ value) for the tolerant species was $2.8 \mathrm{mg} \cdot \mathrm{L}^{-1}$. For the intolerant species, the dissolved oxygen concentration at which $50 \%$ survival occurred was much higher at $4.3 \mathrm{mg} \cdot \mathrm{L}^{-1}$. A conservative interpretation is that intolerant embryos and larvae are indeed more sensitive to low oxygen concentrations and that survival should decline below $4.3 \mathrm{mg} \cdot \mathrm{L}^{-1}$. Early life stages of tolerant species should only begin to show survival effects below $2.8 \mathrm{mg} \cdot \mathrm{L}^{-1}$. For all of these taxa, many of the Illinois streams in which we quantified oxygen concentrations would not be able to consistently provide these conditions for early life stages during summer.

\section{Hierarchical model of oxygen dynamics in streams}

At first glance, identifying critical oxygen minima and medians appears to be a potentially useful way for characterizing systems and, from an applied view, setting legal standards for regulating dissolved oxygen based on the apparent needs of resident organisms (see Chapman 1986). However, as our data for several Illinois streams illustrate, dissolved oxygen shows great spatiotemporal variability and this may influence the ability of organisms to grow and survive. Although we have an incomplete understanding of the mechanisms underlying fluctuations of dissolved oxygen in aquatic systems, the extent of cycling has not been widely documented (although some long-term data sets do exist for metabolism within some stream ecosystems). Our study is among the first to attempt to explore fine-scale daily varia- 


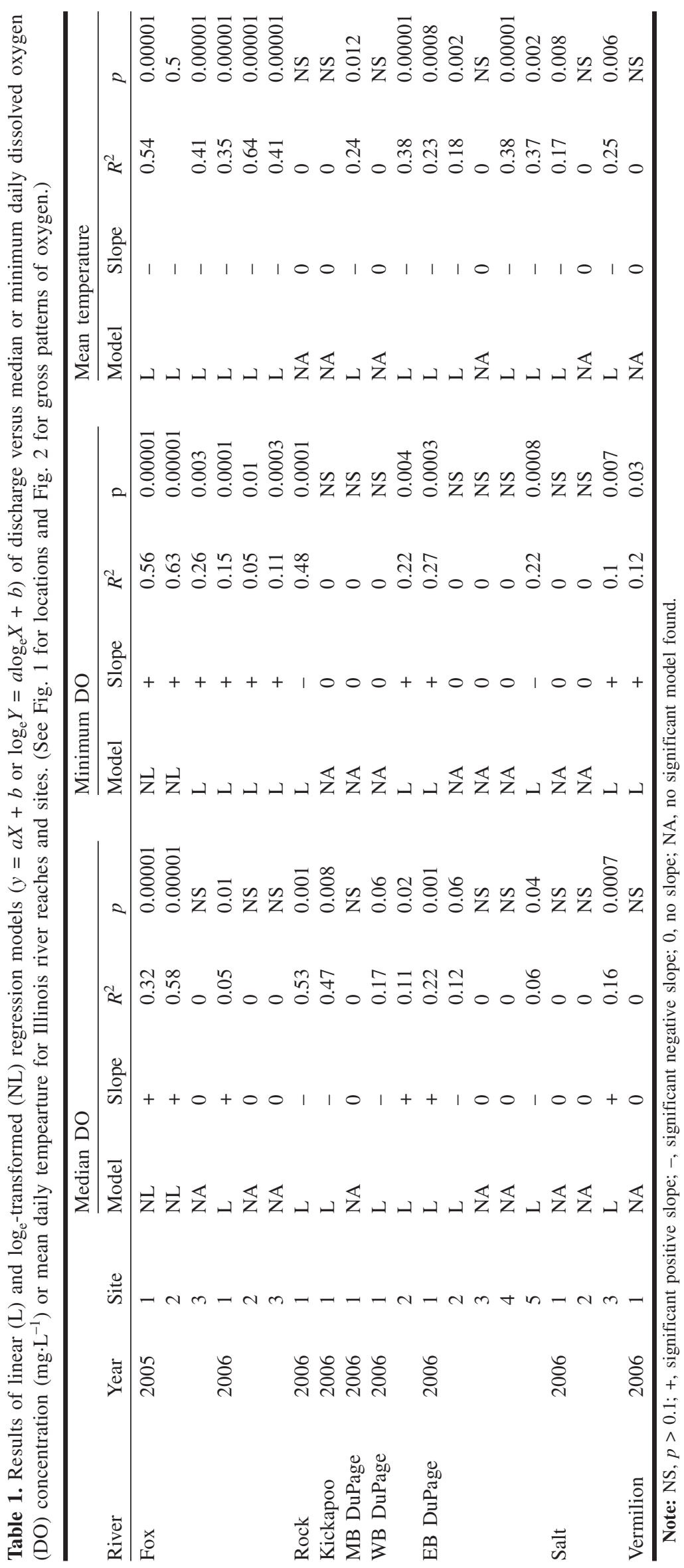


Fig. 7. Slope of regressions between daily median discharge and dissolved oxygen concentration in Illinois streams during 2005 and 2006 as a function of an index of stream size (mean daily discharge per annum). Positive response values indicate an increase in oxygen with increasing discharge. Negative values indicate a decline. See Table 1 for source data.

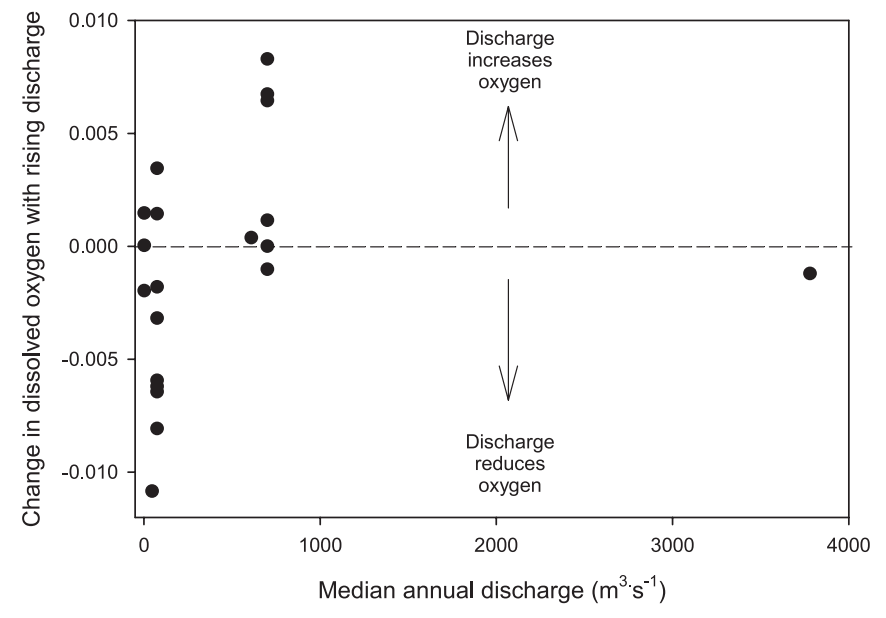

Fig. 8. Percent survival (relative to controls) of "tolerant" (open circle; i.e., largemouth bass, black crappie, white sucker, white bass) and "intolerant" (solid square; i.e., northern pike, channel catfish, walleye, and smallmouth bass) fish larvae and embryos (adapted from Chapman 1986). Model fits were accomplished using nonlinear regression and the assumption of type II (Michaelis-Menten) and logistic relationships for the tolerant and intolerant groupings, respectively.

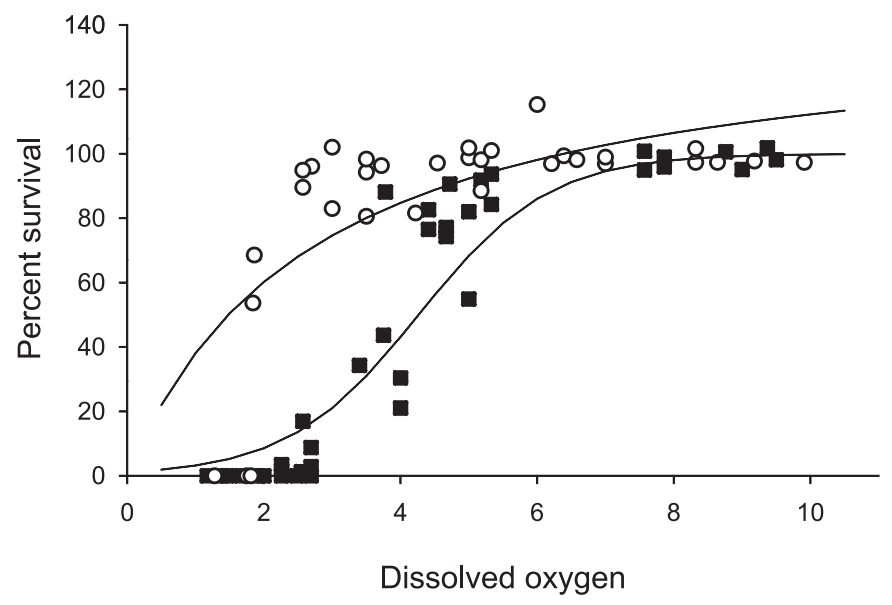

tion among multiple sites and streams rather than relying on temporally and spatially static point estimates. We use these results and those from the literature to generate a set of expectations for the spatial extent, duration, frequency, and magnitude of dissolved oxygen fluctuations in stream ecosystems.

Our expectations for oxygen dynamics (including acute minima and fluctuations) are hierarchical in nature in that we consider dissolved oxygen to be an emergent property of stream ecosystems (Fig. 9). Each factor in the hierarchy constrains oxygen dynamics of the factor below it. Thus, modification to each factor may cascade downward to lower hierarchical factors (Fig. 9).
Fig. 9. Hierarchical model of factors controlling dissolved oxygen (DO) concentrations in streams. Boxes are hierarchical factors. Arrows are the direction of constraints of each level on the adjacent lower factor. Emergent properties are resulting dissolved oxygen dynamics as a function of the constraints imposed by one hierarchical factor on the next.
Hierarchical level

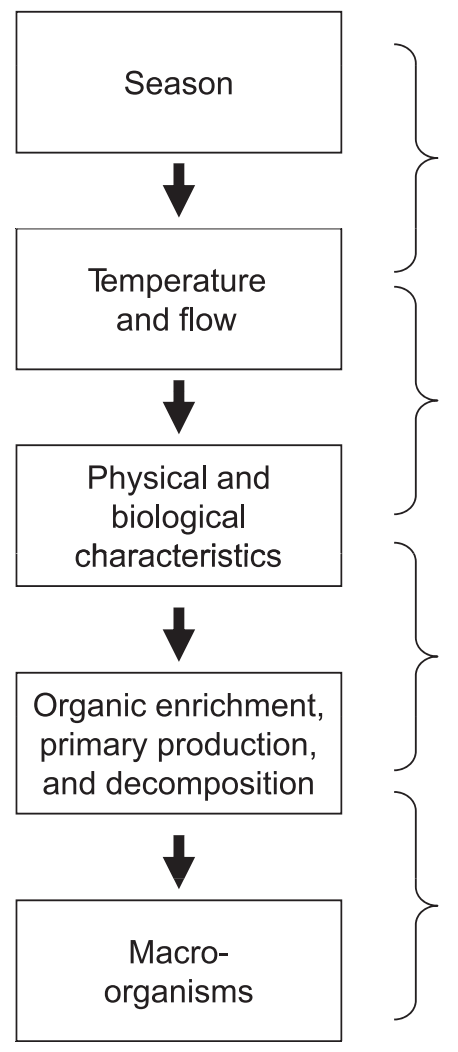

\section{Emergent properties}

Winter: DO and ice cover Spring: Flood pulse and rise in production

Summer: Warm water and aeration

DO depends on availability of flowing water and temperature

DO is response of microbial assemblage; loading depends on constraints imposed by physical characteristics

Bottom-up effects of enrichment may rarely facilitate significant demand for DO by large organisms

\section{Season}

Because the physical properties of oxygen in water are greatly affected by temperature patterns that vary seasonally (as a function of both latitude and altitude), we consider this to be the highest hierarchical level, ultimately constraining dissolved oxygen (Fig. 9). At temperate latitudes, seasonal changes affect patterns of primary production. Typically, during warm months, daily oxygen production and nightly oxygen consumption by autotrophs are responsible for fluctuations such as those seen in Fig. 4 (Walling and Webb 1992). Similarly, ice and snow during cold winters may block the air-water interface, causing depletion of oxygen by heterotrophic activity (Bodensteiner and Lewis 1992). Most aquatic organisms are poikilothermic, and metabolic activity typically rises with rising temperature (Weatherley and Gill 1987). Again, temperature takes a predominant position in the demand for oxygen.

\section{Flow and temperature}

In our view, flow and temperature can influence oxygen independently or, as we have demonstrated, in concert (Fig. 9). High-gradient, swiftly flowing, and turbulent streams should rarely experience severely low oxygen concentrations because of a high rate of exchange with the air. 
However, high temperatures or ice cover may still constrain oxygen availability to organisms under extreme conditions. Our survey of multiple streams demonstrated that the rate by which the volume of water moves through a stream explains more than $50 \%$ of the variation in daily oxygen concentrations (Fig. 6). For the streams in which discharge was positively related to oxygen concentrations, retention of water at low discharge likely allowed sufficient time for autotrophic production to increase and thus increase daily fluctuations in oxygen production and consumption (Walling and Webb 1992). Of course, the accumulation of heat in the streams at low flow also contributed to low oxygen in these systems because the saturation of oxygen varies inversely with temperature. Thus, the combined effect of flow and temperature sets the stage for oxygen dynamics.

\section{Stream geomorphology and related physical characteristics}

The physical template of a stream is likely the next level of organization, which will affect oxygen within the constraints of flow and temperature (Fig. 9). This template is complex and integrates landscape-level (e.g., gradient, catchment geology and land cover, watershed area) to reach-scale (e.g., riffle-pool sequences, sinuosity, substrate composition, groundwater intrusion) factors. All of these affect physical and biological processes such as rates of re-aeration, retention of oxygen, and processing of organic matter. Further, the physical template is the foundation that shapes the complex communities that consume and produce oxygen. Ultimately, the hallmark of a functioning stream would depend on some expected balance between respiration and photosynthesis given the physical template, likely depending on location along the stream continuum (Vannote et al. 1980; Young and Huryn 1999).

A physically simple or homogeneous stream (i.e., a channelized ditch) may rarely experience low dissolved oxygen concentrations with sufficient flow and temperature. A lack of substrate for autotrophs and retention of organic matter allows nutrients to flow through the system without affecting respiration or photosynthesis. Conversely, increased habitat complexity is linked to enhanced producer and consumer communities, increased biological activity, and thus higher nutrient retention (Peterson et al. 2001).

Although enrichment by nutrients may be considered a constraint on this physical habitat (see below), a relationship was absent in a recent survey of Illinois streams (Morgan et al. 2006). Rather, the availability of light, hydrology, and particulate organic matter retention controlled algal biomass and oxygen dynamics. Intact stream communities typically contain multiple trophic levels that include efficient invertebrate and vertebrate herbivores that consume algal production (Power 1990) and are thus capable of dampening daily variation in oxygen concentrations. Habitat that ensures that these consumers successfully complete their life histories is necessary for this top-down control to occur. Reduced biotic integrity, which is often linked to low habitat heterogeneity (Kutka and Richards 1996; Vinson and Hawkins 1998; Stone et al. 2005), should release constraints on algae and increase fluctuations in oxygen production.

The most pristine, functioning, intact streams may experience occasional low flows and extreme temperatures. Under these conditions, dissolved oxygen concentrations may decline to levels that compromise the growth and survival of resident organisms. Thus, another critical habitat component is the presence of contiguous areas that provide refuge from hypoxic areas (e.g., Bodensteiner and Lewis 1992) or sufficient heterogeneity among reaches that allows for recolonization of temporarily affected areas. The absence of this heterogeneity and connectivity should greatly reduce the capacity for streams to rebound from occasional declines in oxygen.

\section{Organic enrichment}

Urban development and agriculture continue to enrich streams with pollutants tied to oxygen consumption such as nitrogen, phosphorus, and organic matter (David and Gentry 2000). Although conventional wisdom might consider nutrient enrichment to be the predominant constraining factor as it may be in lakes (Wetzel 2001), given the literature evidence (Morgan et al. 2006) and our results across systems of varying biotic impairment, it appears that enrichment typically may only be an important constraint of oxygen in streams when temperature, flow, and the physical template create conditions for this to occur (Fig. 9). Of course, beyond some threshold, even highly functioning streams may be unable to resist the effects of poor water quality (e.g., drainages below feedlots or poorly functioning treatment plants). This hierarchical framework highlights the need to focus on flow and habitat when exploring factors affecting oxygen in streams, although the presence of excess nutrients may have a strong impact if flow and habitat are impaired, as is all too typical in many streams.

\section{Macro-organisms}

Large organisms rarely reach densities in which their collective metabolic demand reduces oxygen concentrations. However, organisms such as zebra mussels (Dreissena polymorpha) can become sufficiently abundant to measurably reduce oxygen concentrations in streams (Caraco et al. 2000). If oxygen is constrained by the previous hierarchical levels, then these organisms may have a significant impact on oxygen dynamics, particularly if ample primary production is occurring (Fig. 9).

\section{Implications}

Aquatic organisms vary in their oxygen needs; these requirements vary among taxa and change through life and are likely linked to habitat requirements that provide some temporally and spatially predictable supply of oxygen. Metazoan organisms that persist in stable areas with high aeration and cool temperatures may have the energetic luxury of being less tolerant than counterparts that must contend with the energetic constraints (e.g., synthesizing hemoglobin) of residing in areas of lower oxygen. Knowing how much oxygen is provided by natural, intact systems is of paramount importance, given the alarming hypoxia problems in many systems (e.g., Gulf of Mexico hypoxia; Rabalais et al. 2002) and the need to set expectations for recovery.

Organic enrichment of freshwater and saltwater is clearly an important factor affecting the availability of oxygen to aquatic life. However, we suggest that the ability of streams to provide oxygen as a service to organisms 
can only be met when all the hierarchical levels are not constraining oxygen availability. Temperature can be an oxygen-depleting pollutant when discharged from the cooling pipes of power-generating plants. Similarly, purported increases in seasonal temperatures with global climate change may be considered a burden on the oxygen capacity of streams. Human activities that reduce flow, e.g., the construction of barriers and diversion for freshwater consumption, will further compromise oxygen availability. The physical template of streams also is quite susceptible to human activities and quite critical for oxygen. However, explicit predictions about the interaction among stream structure, organismal responses, and oxygen are not yet possible given a lack of robust observational and experimental data (but see Morgan et al. 2006). As our results and review show, even the "best habitat" may experience occasional localized periods of hypoxia. If no refuge or source populations are present in adjacent areas, or if these areas are isolated, then local populations may become extinct. Hence, fragmentation among sites within stream reaches will likely limit diversity when oxygen becomes occasionally limiting.

We recommend a research focus on how interactions among flow, physical habitat, and nutrients affect patterns of oxygen in streams across multiple spatiotemporal scales. As our survey illustrates, oxygen is notoriously variable and can vary markedly among sites within reaches and between years. In our view, even continuous information about oxygen concentrations should be used by policymakers in a diagnostic, rather than regulatory, capacity when streams are assessed for compliance with aquatic life expectations. Oxygen is a result of the underlying interactions among hierarchical levels. These underlying causes should be the regulatory focus rather than attempting to adhere to some acute or chronic value for oxygen concentration.

The lack of sound information about how spatial and temporal dynamics of oxygen in streams affect stream organisms is surprising. For example, we cannot yet translate the dynamics of oxygen in our survey to the presence or absence of aquatic organisms in the streams (but see Smale and Rabeni $1995 a, 1995 b)$. Thus, to assess the consequences of oxygen dynamics in streams, responses of organisms, e.g., movement or recolonization, as well as sublethal responses such as growth and reproduction, need to be quantified. Further, assessments of oxygen tolerance and the impact of low oxygen levels on lotic organisms need to be performed in environmentally relevant ways (e.g., responses of riffle-dwelling species should not be studied in microcosms without flow). Ultimately, a more complete understanding of the linkages among oxygen needs, life histories, and habitat requirements will allow us to better identify and use indicators of biological integrity in these complex systems.

\section{Acknowledgements}

This research was the result of the authors' multiyear participation in development of a dissolved oxygen standard for Illinois. Data were collected by members of the Illinois Association of Wastewater Agencies and the DuPage River Salt
Creek Workgroup. The ideas contained herein are the result of many conversations with J. Michael Callahan and members of the ILEPA, Illinois Department of Natural Resources, and US Geological Survey. Questions posited by the Illinois Pollution Control Board were quite insightful. Gary Chapman and three anonymous reviewers also provided helpful comments during this process.

\section{References}

Barnwell, T.O., and Brown, L.C. 1987: The enhanced stream water quality models QUAL2E and QUAL2E-UNCAS: documentation and user manual. US Environmental Protection Agency, Washington, DC, EPA/600/3-87/007.

Bodensteiner, L.R., and Lewis, W.M. 1992. Role of temperature, dissolved oxygen, and backwaters in the winter survival of freshwater drum (Aplodinotus grunniens) in the Mississippi River. Can. J. Fish. Aquat. Sci. 49: 173-184.

Caraco, N.F., Cole, J.J., Findlay, S.E.G., Fischer, D.T., Lampman, G.G., Pace, M.L., and Strayer, D.L. 2000. Dissolved oxygen declines in the Hudson River associated with the invasion of the zebra mussel (Dreissena polymorpha). Environ. Sci. Technol. 34: 1204-1210.

Carlson, R.E. 1977. A trophic state index for lakes. Limnol. Oceanogr. 23: 361-369.

Chapman, G. 1986. Ambient water quality criteria for dissolved oxygen. US Environmental Protection Agency, Office of Water Regulations and Standards, Washington, DC, EPA 440/5-86-003.

Chen, L., Heath, A.G., and Neves, R.J. 2001. Comparison of oxygen consumption in freshwater mussels (Unionidae) from different habitats during declining dissolved oxygen concentration. Hydrobiologia, 450: 209-214.

Cooper, C.M. 1993. Biological effects of agriculturally derived surface water pollutants on aquatic systems - a review. J. Environ. Qual. 22: 402-408.

Cushing, C.E., and Allan, J.D. 2001. Streams: their ecology and life. Academic Press, San Diego, California.

Danylchuk, A.J., and Tonn, W.M. 2003. Natural disturbances and fish: local and regional influences on winterkill of fathead minnows in boreal lakes. Trans. Am. Fish. Soc. 132(2): 289-298.

David, M.B., and Gentry, L.E. 2000. Anthropogenic inputs of nitrogen and phosphorus and riverine export for Illinois, USA. J. Environ. Qual. 29: 494-508.

Erikson, C.H., Lamberti, G.A., and Resh, V.H. 1996. Aquatic insect respiration. In An introduction to the aquatic insects of North America. Edited by R.W. Merritt and K.W. Cummins. Kendall/Hunt, Dubuque, Iowa. pp. 29-40.

Fox, H.M., and Sidney, J. 1953. The influence of dissolved oxygen on the respiratory movements of caddis larvae. J. Exp. Biol. 30: $235-237$.

Fox, H.M., Wingfield, C.A., and Simmonds, B.G. 1937. The oxygen consumption of ephemerid nymphs from flowing and from still waters in relation to the concentration of oxygen in the water. J. Exp. Biol. 14: 210-218.

Garvey, J.E., Marschall, E.A., and Wright, R.A. 1998. From star charts to stoneflies: detecting relationships in continuous bivariate data. Ecology, 79: 442-447.

Gaufin, A.R. 1973. Water quality requirements of aquatic insects. US Environmental Protection Agency, Washington, DC, EPA 660/3-73-004.

Groschen, G.E., and King, R.B. 2005. Evaluation of measurements collected with multi-parameter continuous water-quality moni- 
tors in selected Illinois streams, 2001-3. US Geological Survey, Scientific Investigations Report No. 2005-5060.

Hauer, F.R., and Lamberti, G.A. 2006. Methods in stream ecology. 2nd ed. Academic Press, New York.

Illinois Environmental Protection Agency. 2004. Illinois water quality report. Illinois Environmental Protection Agency, Springfield, Illinois. IEAP/BOW/04-006.

Kapoor, N.N. 1976. The effect of copper on the oxygen consumption rates of the stonefly nymph, Phasganophora capitata (Pictet) (Plecoptera). Zool. J. Linnean Soc. 59: 209-215.

Kutka, F.J., and Richards, C. 1996. Relating diatom assemblage structure to stream habitat quality. J. N. Amer. Benthol. Soc. 15: 469-480.

Maki, A.W., Stewart, K.W., and Silvey, J.K.G. 1973. The effects of dibrom on respiratory activity of the stonefly, Hydroperla crosbyi, hellgrammite, Corydalus cornutus, and the golden shiner, Notemigonus crysoleucas. Trans. Am. Fish. Soc. 102: 806-815.

McCune, B., and Grace, J.B. 2002. Analysis of ecological communities. MJM Software, Gleneden Beach, Oregon.

Moore, W.G. 1942. Field studies on the oxygen requirements of certain fresh-water fishes. Ecology, 23(3): 319-329.

Morgan, A.M., Royer, T.V., David, M.B., and Gentry, L.E. 2006. Relationships among nutrients, chlorophyll-a, and dissolved oxygen in agricultural streams in Illinois. J. Environ. Qual. 35(4): 1110-1117.

Nebeker, A.V. 1972. Effects of low oxygen concentration on survival and emergence of aquatic insects. Trans. Am. Fish. Soc. 101: 675-679.

Owens, M., Edwards, R., and Gibbs, J. 1964. Some reaeration studies in streams. Int. J. Air Water Pollut. 8(8/9): 469-486.

Perterka, J.J., and Kent, J.S. 1976. Dissolved oxygen, temperature, and survival of young at fish spawning sites. Environmental Protection Agency, Washington, DC, Ecological Research Series Report No. EPA-600/3-76-113.

Peterson, B.J., Wollheim, W.M., Mulholland, P.J., Webster, J.R., Meyer, J.L., Tank, J.L., and Marti, E. 2001. Control of nitrogen export from watersheds by headwater streams. Science (Washington, D.C.), 292: 86-90.

Power, M.E. 1990. Effects of fish in river food webs. Science (Washington, D.C.), 250: 811-814.

Rabalais, N.N., Turner, R.E., and Scavia, D. 2002. Beyond science into policy: Gulf of Mexico hypoxia and the Mississippi River. Bioscience, 52: 129-142.

Scott, W.B., and Crossman, E.J. 1998. Freshwater fishes of Canada. Galt House Publications, Oakville, Ontario.

Smale, M.A., and Rabeni, C.F. 1995a. Hypoxia and hyperthermia tolerances of headwater stream fishes. Trans. Am. Fish. Soc. 124: $698-710$.

Smale, M.A., and Rabeni, C.F. 1995b. Influences of hypoxia and hyperthermia on fish species composition in headwater streams. Trans. Am. Fish. Soc. 124: 711-725.
Stone, M.L., Whiles, M.R., Webber, J.A., Williard, K.W.J., and Reeve, J.D. 2005. Macroinvertebrate communities in agriculturally impacted southern Illinois streams: patterns with riparian vegetation, water quality, and in-stream habitat quality. J. Environ. Qual. 34: 907-917.

Sweeney, B.W., and Vannote, R.L. 1981. Ephemerella mayflies of White Clay Creek: bioenergetic and ecological relationships among six coexisting species. Ecology, 62: 1353-1369.

Tonn, W.M., and Paszkowski, C.A. 1986. Size-limited predation, winterkill, and the organization of Umbra-Perca fish assemblages. Can. J. Fish. Aquat. Sci. 43: 194-202.

Tonn, W.M., Magnuson, J.J., Rask, M., and Toivonen, J. 1990. Intercontinental comparison of small-lake fish assemblages: the balance between local and regional processes. Amer. Nat. 136: $345-375$.

Vannote, R.L., and Sweeney, B.W. 1980. Geographic analysis of thermal equilibria: a conceptual model for evaluating the effects of natural and modified thermal regimes on aquatic insect communities. Amer. Nat. 115: 667-695.

Vannote, R.L., Minshall, G.W., Cummins, K.W., Sedell, J.R., and Cushing, C.E. 1980. The river continuum concept. Can. J. Fish. Aquat. Sci. 37: 130-137.

Vellidis, G., Barnes, P., Bosch, D.D., and Cathey, D.D. 2006. Mathematical simulation tools for developing dissolved oxygen TMDLs. Trans. Asabe, 49(4): 1003-1022.

Vinson, M.R., and Hawkins, C.P. 1998. Biodiversity of stream insects: variation at local, basin, and regional scales. Ann. Rev. Entom. 43: 271-293.

Walling, D.E., and Webb, B.W. 1992. Water quality. I. Physical characteristics. Blackwell Scientific, Oxford, UK.

Wang, H., Hondzo, M., Xu, C., Poole, V., and Spacie, A. 2003. Dissolved oxygen dynamics of streams draining an urbanized and an agricultural catchment. Ecol. Model. 160(1-2): 145-161.

Watters, G.T. 1999. Freshwater mussels and water quality: a review of the effects of hydrologic and instream habitat alterations. In Proceedings of the First Freshwater Mollusk Conservation Society Symposium, 16-20 March 1999, Chattanooga, Tennessee. Ohio Biological Survey, Columbus, Ohio. pp. 261-274.

Weatherley, A.H., and Gill, H.S. 1987. The biology of fish growth. Academic Press, London, UK.

Wetzel, R.G. 2001. Limnology: lake and river ecosystems. Academic Press, New York.

Wu, R.S.S. 2002. Hypoxia: from molecular responses to ecosystem responses. Marine Pollut. Bull. 45: 35-45.

Wu, R.S.S., Zhou, B.S., Randall, D.J., Woo, N.Y.S., and Lam, N.Y.S. 2003. Aquatic hypoxia is an endocrine disruptor and impairs fish reproduction. Environ. Sci. Technol. 37: 1137-1141.

Young, R.G., and Huryn, A.D. 1999. Effects of land use on stream metabolism and organic matter turnover. Ecol. Appl. 9(4): 13591376. 